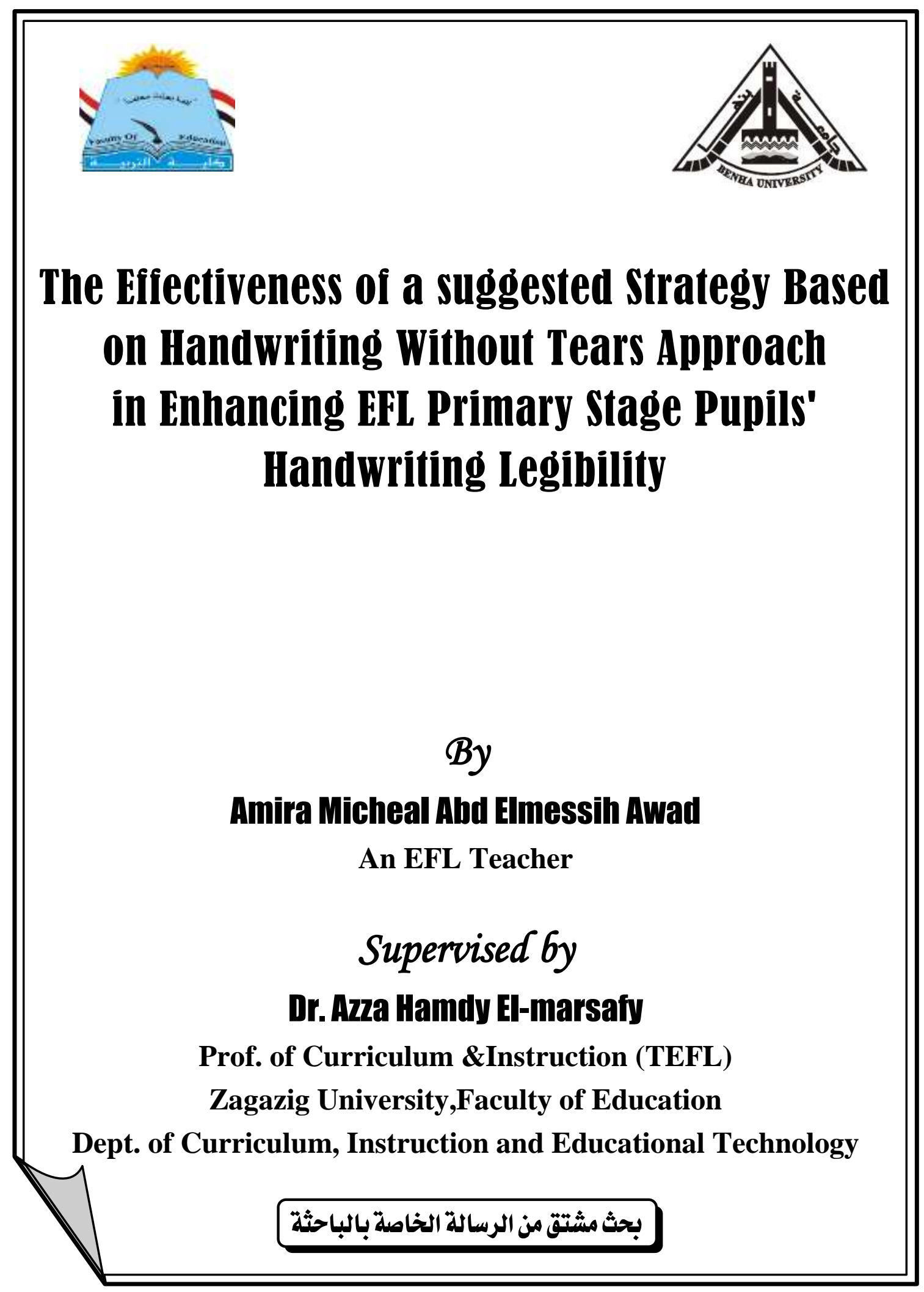




\title{
The Efiectiveness of a suggested Strategy Based on Handwriting Without Tears Approach in Enhancing EFL Primary Stage Pupils' Handwriting Leg̉ibility
}

\section{By}

\section{Amira Micheal Abd Elmessih Awad}

\author{
An EFL Teacher
}

Supervised by

\section{Dr. Azza Hamdy El-marsafy}

Prof. of Curriculum \&Instruction (TEFL)

Zagazig University,Faculty of Education

Dept. of Curriculum, Instruction and Educational Technology

\section{Abstract}

This study aimed to investigate the effectiveness of a proposed strategy based on Handwriting Without Tears Approach in enhancing (44) primary stage pupils' handwriting legibility. The participants were equally divided into experimental and control groups at Kafr Sakr Formal Language School, Sharkia Governorate. To achieve the aim of the research, the researcher designed Handwriting Checklist, Pre-post Writing tests, Pupil's Book and Teacher's Guide based on the suggested strategy. The experimental group was taught via the suggested strategy in the first term (2019) for one period weekly which lasted for 90 minutes, while the control group received regular instruction. The results of the study indicated that the suggested strategy proved to be effective in improving the experimental group handwriting legibility than the control group. This study recommended that handwriting must receive an insightful emphasis especially at the primary stage.

Keywords: Handwriting Without Tears Approach, primary stage pupils, handwriting legibility, Egypt. 


\section{Introduction}

Writing is considered a significant part of our life, whether in the workplace or school, as a hobby or in personal communication. It helps the writer express feelings and thoughts to other people in a reasonably perpetual form. Personal writing builds a relationship between the writer and his readers in a different way from oral communication, and it assists people to consolidate their thoughts on seeing them on paper or on a screen.

Legible writing that can be produced comfortably, at speed and with little conscious effort gives the pupil the opportunity to attend to the higher-level aspects of writing composition and content. This is significant when assessments are based on written work, principally in time-limited written examinations, which remain as the main form of assessment for many formal qualifications. Without legible handwriting, pupils may miss out on learning chances and under-achieve academically (National Handwriting Association, n.d).

The world-renowned Cambridge University is considering eradicating handwritten exams after 800 years. University officials may demand students to use computer in answering their written exams rather than use a pen. The move follows complaints from the staff members who say they are finding examination papers increasingly illegible due to poor handwriting. Staff members say today's students primarily use laptops in lectures and tutorials instead of pens. Students are unable to write by hand. One of the staff members said asking students to hand-write exams really causes them physical difficulties. The muscles in their hand are not used to write extensively for long periods of two to three hours. A Cambridge University lecturer, Dr Sarah Pearsall, told Britain's 'Daily Telegraph' newspaper that handwriting was becoming a "lost art". She said: "Twenty years ago, students routinely [wrote] by hand several hours a day, but now they write virtually nothing by hand, except exams." She added: "We have been concerned for years about the declining handwriting problem. There has clearly been a downward trend. It is difficult for both the students and the examiners as it is difficult to read these exam papers." Dr Pearsall states that some students' handwriting is so illegible that they had to return to the colleges over the summer to read their answers to examiners who could not read their handwriting

(Breaking News English, 2017). 
The brain engages in a different way when students write something by hand as opposed to typing it on a keyboard or by touching a screen. Studies show that writing fosters memory; pupils retain learning better on expressing new ideas through handwriting instead of typing. Being able to write naturally enables the mind to concentrate more fully on a topic. Struggling with handwriting takes valuable brain energy away from any writing task, but when that handwriting is mastered, it makes all the difference. Skilled, fluid handwriting is an advantage to learning. Learning the alphabet by interacting with each letter in various physical ways assists pupils imprint and retain the letters and the letter sounds for easier recall when learning to read. Learning letters on a screen engages at most the eyes and the fingertips. It is not possible to tell one letter from another by the shape of the keys. Learning letters through writing them involves several tactile experiences, engaging the fine-motor muscles of the fingers and hand, and larger muscles of the arm and body, as well as the eyes (Living Education Contributor, 2015).

University students find it easier to retain information when using books and handwriting notes rather than using computers, according to a survey of European and Asian students. A study of almost 650 students from 10 countries indicated that while computers are now used widely in teaching and learning at universities, students still see the profits of reading and writing with paper. The chief results show that there are many points of similarities between the countries studied but that some use pen and paper less whereas others are more prepared to use hand writing, this may relate to the accessibility and use of digital technologies as well as to personal learning styles. Reading and writing competencies are changing with the use of digital technologies but students still see profits of reading and writing with paper which they continue to use, especially to express private emotions and warm feelings. This research provides new learning about the contrasting usage of paper and digital media within an instructional rather than business setting. These surveys provided the foundation for the design and analysis of a follow up quantitative study and for further exploration of this important research topic within the countries surveyed, particularly in social sciences and pedagogical studies. (Vincent, Jane 2016) . 


\section{The format of Handwriting without Tears Approach. $\square$}

Learning in Handwriting without Tears follows developmentallybased learning steps.

\section{- Step 1: Readiness}

The first stage is called Readiness and is designed for Pre- $\mathrm{K}$ and $\mathrm{K}$ pupils. It contains very tactile, sensory-oriented props and activities designed to increase knowledge of and familiarity with letters and numbers. It contains, many things such as a musical CD, large floor mat, wooden letter pieces, letter cards, slate chalk-boards, and dough for rolling into letters and numbers. These activities also compliment pupils' gross and fine motor skill development.

\section{- Step 2: Printing}

The next step includes learning how to print, and use workbooks. It can be begun in late kindergarten and progresses through grades 1 and 2 . The workbooks contain interesting illustrations, double lines to guide letter-sizing, and vertical (vs. slanted) letters. Some tactile facilitators such as wooden letter pieces continue to be used.

\section{- Step 3: Cursive}

In grades 3 and 4, the workbooks target the development of cursive writing. The early construction is on lower-case, high-frequency letters, then finally whole words, sentences and paragraphs. There are different chances for review and assessment.

The lessons introduced at all stages are clearly laid out for parents and teachers, and are organized so that they would optimally take about ten minutes daily.

The Handwriting Without Tears ${ }^{\circledR}$ developmental teaching order assists pupils master handwriting skills in the easiest, most effective way. As a result, pupils can transition rapidly from learning the mechanics of handwriting to concentrating on content and meaning-in all subjects. printing is taught first. After printing is mastered, the cursive connections are added (The Handwriting Without Tears K-5, 2017).

Although the majority of teachers agree that direct handwriting instruction should be applied into the school day, studies have showed 
that a large percentage of teachers don't feel knowledgeable about aspects that influence pupils' writing development (Graham, Harris, Mason, Fink, Moran \& Saddler, 2008). Teachers find difficulty to come up with strategies and/or methods of teaching handwriting in unconventional ways. This lack of teaching training and/or teaching practices raises concerns about the quality of handwriting instruction for pupils in the early primary grades (Graham et. al, 2008).

\section{Handwriting legibility}

Handwriting is a significant functional activity that needs to be performed by pupils in lower grades of primary school, and it is an important ability for academic achievements1. However, because the time period in which pupils attempt handwriting differs according to the maturity of the nervous system, environmental experience, and the standard of interest in letters, it is significant to verify in the early stages of development whether pupils have difficulties in performing the task of handwriting. In order to evaluate the ability of handwriting performance in young pupils, different dimensions must be taken into consideration including the domain of handwriting, legibility, speed, and ergonomic factors. Among these dimensions, legibility signifies the legibility of their handwriting. The factors that affect handwriting legibility include the shape, the size, the arrangement of the letters, and the amount of space between the letters. Before beginning the process of handwriting, pupils need to develop readiness skills for forming letters, such as the comprehensive capabilities of different sensor motor systems, the development of large and small muscles, visual perception, fine motor skills, and in-hand manipulation skills. If pupils without adequate development of such readiness skills learn handwriting, they are at risk of developing bad handwriting habits, which may result in problems in developing handwriting legibility. According to the previous studies, which highlight the significance of acquiring readiness skills before starting handwriting, there are different factors connected to the issues involved in the present study. Among these factors, fine motor skills allow for the demonstration of good handwriting legibility through the ability to control a handwriting tool with speed and accuracy over the course of activities such as fine motor precision, manual dexterity, and in-hand manipulation As such, fine motor skills are important for pupils before developing the 
repeated behavior of holding suitable writing utensils However, previous studies have focused on the factors of and correlation between visual perception and visual motor integration (Sang-Min Seo, MS,2018)

The researcher held a meeting with $10 \mathrm{EFL}$ in-service teachers at the Governmental Language Schools in Kafer Sakr and Hehia ,Sharkia Governorate; all of them assured that they never had training whether at the university nor at the training programs held after their graduation on modern scientific bases of the writing mechanisms, which is reflected negatively on their pupils' learning to that skill. They stated that the pupils, who could not master this skill, face great difficulty in reading and in turn, they are neither being able to understand the content they study nor answer their written exams in a legible way. So, they will fail in their academic life.

\section{Statement of the problem}

The problem of this study can be stated in the weakness of EFL primary stage pupils' handwriting skills as the EFL in-service teachers at these schools never use scientific methods in teaching handwriting skills. The previously mentioned studies indicate that pupils who master handwriting are better, and more creative writers. The earlier EFL teachers teach pupils to master handwriting, the more likely they are to succeed in school, and write with speed and ease in all subjects.

\section{Questions of the study}

This study was an attempt to find an answer to the following main question:

"What is the effectiveness of a proposed strategy based on Handwriting Without Tears approach in enhancing primary stage pupils' handwriting legibility?"

The following sub-questions were derived from the above mentioned question:

1- What are the handwriting skills required for EFL primary stage pupils?

2- To what extent do EFL primary stage pupils possess these skills?

3- How can a suggested strategy based on Handwriting Without Tears Approach be designed? 
4- What is the effect of the suggested strategy based on Handwriting Without Tears Approach on EFL primary stage pupils' handwriting legibility?

\section{Procedures of the study:}

\section{Responding to the study questions, the following were conducted:}

1- Reviewing the literature related to the different variables of the study.

2- Selecting the experimental and control groups from the Formal Language Primary Schools, Sharkia Governorate.

3- Designing the instruments of the study which include
a) The handwriting sub- skills checklist needed for EFL primary stage pupils.
b) A Pre Handwriting Test for both the experimental and control groups.

4- Submitting the instruments to the jury members to validate them.

5- Pre administering the handwriting test .

6- Administering the post handwriting test for both groups.

7- Comparing both administrations results.

8- Treating the results statistically.

9- Discussing and interpreting the results and introducing conclusion, recommendations and further studies

\section{Materials of the study:}

a) Suggested learning activities designed by the researcher based on Handwriting Without Tears Approach to enhance EFL primary stage pupils' handwriting skills .

b) Teacher's Guide.

c) Handwriting Without Tears Proficiency Rubric.

d) Cursive Handwriting Rubric

e) Handwriting Legibility Rubric. 


\section{Method of the study:}

The researcher adopted quasi-experimental design.

\section{Significance of the study:}

1- The use of this suggested strategy would hopefully benefit the EFL primary stage pupils to enhance their handwriting legibility

2- The use of this suggested strategy would hopefully benefit the EFL in-service teachers to adopt scientific approaches and methods to teach handwriting at the primary stage.

3- This study may be a starting point for curriculum designers to hold training sessions for EFL in-service teachers at the primary stage on how to adopt this suggested strategy to enhance pupils' handwriting legibility.

4- This study might be a starting point for staff members at the English sections at the Faculties of Education to include these recent approaches of teaching handwriting in TEFL curriculum to develop their handwriting skills.

\section{Delimitations of the Study:}

The current study was delimited to :

- The participants were 44 EFL fourth grade primary stage pupils at Kafr Sker Formal Language Primary School, Sharkia Governorate, who were equally divided into experimental and control groups.

- The experiment was carried out in the first term of the academic year (2019-2020)

\section{Definition of Terms:}

\section{Handwriting Without Tears Approach (program):}

- The Handwriting Without Tears ${ }^{\circledR}$ program provides the child with the necessary skills to be successful with handwriting in school. Developed by Jan Olsen, an occupational therapist, Handwriting Without Tears ${ }^{\circledR}$ is a developmentally based program designed to progress a child's fine motor skills along with visual skills through fun and interactive activities (Children's Hospital Pittsburgh of UPMC, 2017). 
- The Handwriting without Tears program is designed to teach children how to write in a manner than it is readable without the struggle that many face with a home school handwriting curriculum. It is hands on and is designed from Pre-k through 5th grade. The program starts with blocks which allow children to learn how the various parts of letters are put together before moving on to actual practice on boards, handwriting worksheets and other materials. It also has a sing along program. It is also designed for students of all learning styles (Homeschool curriculum.org,2017).

- The Handwriting without Tears program can be defined operationally as a handwriting program that was taught at Kafr Sker Formal Language Primary School, Sharkia Governorate, which was used in making legible and fluent handwriting an easy and automatic skill for pupils.

\section{Writing Legibility}

- The quality of being clear enough to read.

https://www.lexico.com/definition/legibility

- A quality of writing (print or handwriting) that can be easily read https://www.audioenglish.org/dictionary/legibility.htm

- Writing legibility can be defined operationally as the quality of type that affects the perceptibility of a word, line, or paragraph of printed matter of the pupils at Kafr Sker Formal Language Primary School, Sharkia Governorate.

\section{Results of the study}

\section{Comparing the pre-test results of both groups $\square$}

Before experimentation, (control group and the experimental group) were pre-tested to make sure that the two groups were equal in their Handwriting Legibility.

The statistical package for social science program (SPSS Ver.26) was used to calculate the differences between the mean scores of the control and experimental groups on the pre and post testing. The 
researcher used t-test to calculate the t-values for testing the differences between the mean scores of the study groups.

\section{Pre Test statistics:}

Before experimentation, both groups (control and experimental) were pre-tested to make sure that both groups were equal in Handwriting Legibility.

Table (1): Pre t-test Handwriting Legibility for the control and the experimental groups in the EFL Handwriting test.

\begin{tabular}{|c|c|c|c|c|c|c|c|}
\hline Skill & Group & $\mathbf{N}$ & $\mathbf{M}$ & S.D & df & t-value & Sig \\
\hline \hline \multirow{2}{*}{$\begin{array}{l}\text { 2-Handwriting } \\
\text { Legibility }\end{array}$} & Control & 22 & 1.68 & .568 & \multirow{2}{*}{42} & .732 & $.468^{*}$ \\
\cline { 2 - 7 } & Experimental & 22 & 1.82 & .664 & & & \\
\hline
\end{tabular}

*Non significant.

Pre-testing results in table (1) shows that t-value (.732) is not significant at the level of 0.01 . So, there was no significant difference between the control and the experimental group in Handwriting Legibility in pre-test.

Table (4): Pre t-test for the control and the experimental groups in overall EFL Handwriting skills test.

\begin{tabular}{|c|c|c|c|c|c|c|c||}
\hline Skill & Group & $\mathbf{N}$ & $\mathbf{M}$ & S.D & df & t-value & Sig \\
\hline \hline $\begin{array}{c}\text { Overall EFL } \\
\text { Handwriting skills } \\
\text { Pronunciation }\end{array}$ & Control & 22 & 2.91 & .868 & & & \\
\cline { 2 - 6 } & Experimental & 22 & 3.00 & .816 & 42 & .358 & $.722^{*}$ \\
\hline
\end{tabular}

*Non significant.

Pre-testing results in table (2) shows that t-value (.358) is not significant at the level of 0.01 . So, there was no significant difference between the control and the experimental groups in overall EFL handwriting skills in the pre-test. 


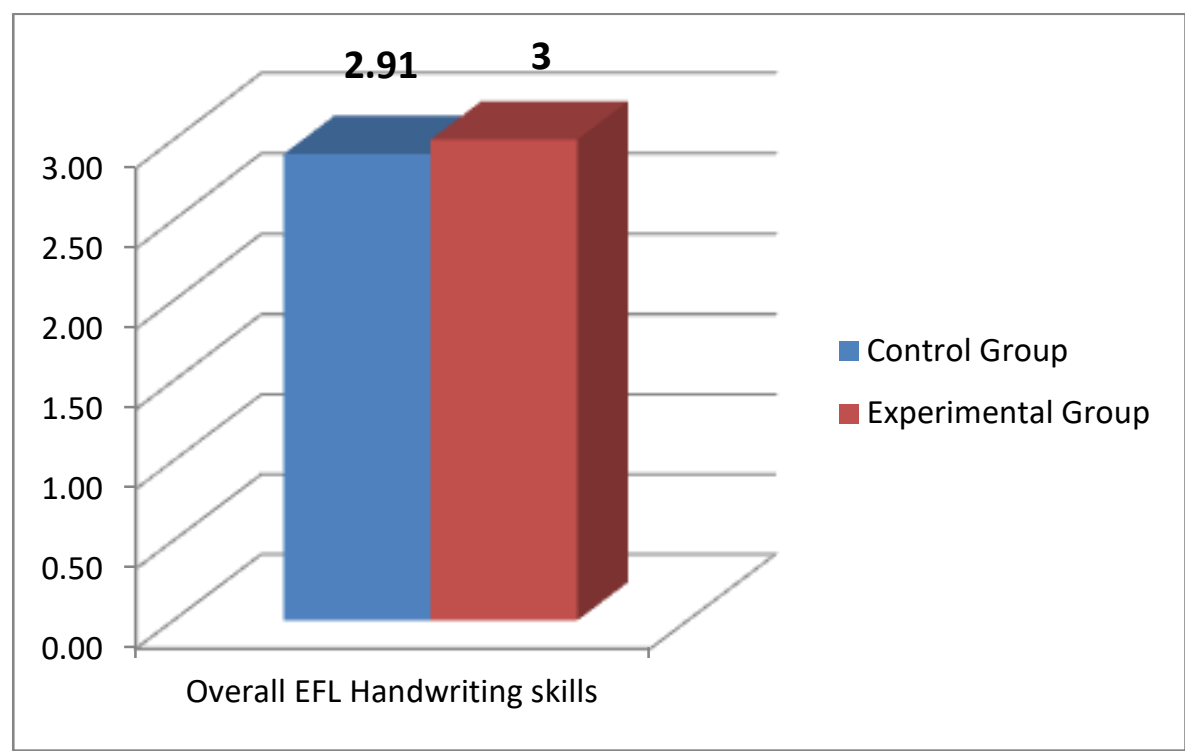

Figure (2): A comparison of the mean scores for the control and the experimental groups in the pre-test of overall EFL Handwriting skills.

The previous figure indicates that both groups were homogeneous as far as overall EFL Handwriting skills is concerned and that they were at the same level before implementing the Proposed Strategy based on Handwriting without Tears Approach.

\section{The pre/post handwriting test}

\section{Purpose of the test}

The researcher designed "The Handwriting Skills Test", which was utilized as a pre and post-test to assure that the pupils of the experimental and control groups were of the same standard before starting the experiment. The post-test was used to identify whether pupils' handwriting skills in the experimental group were developed as a result of the proposed strategy based on Handwriting Without Tears Approach.

\section{Description of the test}

The handwriting skills test consisted of one paragraph. The pupils of the control and the experimental groups were asked to write from four to six sentences about one of the topics they study in their English language textbook (Star Plays 4), the test was corrected based on the items mentioned in the Handwriting Checklist. 


\section{Sources of the writing test}

The handwriting test was assigned based on the following sources:

a) Reviewing related studies related to the design of EFL handwriting tests.

b) The handwriting skills of the final version of handwriting checklist.

c) The English Language textbook "Star plays 4"

\section{Validity of the test}

To measure the validity of the handwriting test, it was submitted to $20 \mathrm{EFL}$ specialists from different Egyptian universities. It was proved to be valid for assessing the handwriting legibility skills of the pupils at Kafr Sakr Formal Language School, Sharkia Governorate as it was assigned from the English language textbook "Star plays 4".

\section{Reliability of the EFL Handwriting Legibility skills test:}

Table (2): The reliability of EFL Handwriting Legibility skills test:

\begin{tabular}{|c|c|c|c||}
\hline Test & $\begin{array}{c}\text { Spearman and } \\
\text { Brown }\end{array}$ & $\begin{array}{c}\text { split half } \\
\text { technique }\end{array}$ & $\begin{array}{c}\text { Alpha - } \\
\text { Cronbach }\end{array}$ \\
\hline \hline $\begin{array}{c}\text { Handwriting Legibility } \\
\text { Skills Test }\end{array}$ & 0.88 & 0.77 & 0.84 \\
\hline
\end{tabular}

The reliability of the test was measured by using different methods. The first one was Alpha -Cronbach way. The results revealed that the value of Alpha was (0.84) which indicates a statistically reliable value. The researcher also used split half technique. The results revealed that the reliability of the test was (0.77). The researcher also used Spearman and Brown. The results revealed that the reliability of the test was (0.88) which indicates a statistically reliable value. See the previous table.

\section{Results of the study and interpretation of these results}

This study aimed mainly to investigate utilizing a proposed strategy based on Handwriting Without Tears Approach to enhance fourth grade primary stage pupils' handwriting legibility at Kafr Sakr Formal Language School, Sharkia Governorate. The researcher prepared a suggested strategy based on the aforementioned approach, this strategy 
was used in teaching to the experimental group for a complete term (22\9 12019: 9\12\2019), while the control group received regular instruction. The researcher prepared a student's book and a teacher's guide that adopt the steps and procedures of the suggested strategy.

The results of the study indicated that the experimental group outperformed the control one in the post handwriting test. Hence, the significance differences between the two groups are resulted from utilizing the suggested strategy based on Handwriting Without Tears Approach on EFL primary stage pupils' handwriting legibility at Kafr Sakr Formal Language School, Sharkia Governorate.

\section{Interpretation of the results:}

The results of the present study were discussed with reference to the related literature and validation of the hypotheses.

The researcher prepared a student's handbook and a teacher's guide based on Handwriting Without Tears Approach to develop EFL primary stage pupils' handwriting legibility at Kafr Sakr Formal Language School, Sharkia Governorate.

The student's book contained 14 lessons that were tailored according to the steps and procedures of the aforementioned approach .The results of the study revealed the positive effect of the suggested strategy on the handwriting legibility of experimental group.

The results of this study are consistent with many studies which indicated the positive effect of Handwriting Without Tears Approach on enhancing primary stage pupils' legibility such as (Owens, L.L. 2004, Guy, Jodie M. 2003, Smith- Zuzovsky, N., \& Exner, C.E. 2004, SteMarie, D.M., Clark, S. E., Case-Smith, J., Holland, T., Lane, A., \& White, S. 2012, Denton, P.L., Cope, S. \& Moser, C. 2006, Weintraub, N., Yinon, M, Hirsch, I.B. \& Parush, S. 2009, and Young, S., Laxman, K. 2014)

The results also stress the importance of handwriting even at this digital age; The EFL teachers must pay much attention to handwriting, 
Especially at the primary stage as mastering handwriting help them succeed and achieve good results in the education process. In fact this aspect is consistent with the many studies which indicate that handwriting helps develop cognitive and motor skills, Boost memory, improve language and reading skills, exercise the brain, and give confidence.

\section{Conclusions: $\square$}

This study aimed to scrutinize the utilization of a proposed strategy based on Handwriting Without Tears Approach to enhance (44) primary stage pupils' handwriting fluency and legibilityThe results of the study were treated statistically. The results indicated that the suggested strategy proved to be effective in enhancing the experimental group handwriting legibility than the control group. This study recommended that handwriting must receive a profound interest especially at the primary stage, in addition to adopting the suggested strategy in teaching handwriting at the primary stage in Egypt. The Ministry of Education and Faculties of Education must pay enough attention to teaching handwriting. 


\section{References $\square$}

- Breaking News English, (2017) Lesson on Handwriting, Cambridge University may end handwritten exams. https://breakingnewsenglish.com/1709/170913-handwriting.html

- Case-Smith, J., Holland, T., \& Bishop, B. (2011). Effectiveness of an integration handwriting program for first grade students: A pilot study. American Journal of Occupational Therapy, 65, 670-678.

- Children's Hospital Pittsburgh of UPMC, (2017). Handwriting Without Tears Program at Center for Independence. http://www.chp.edu/ourservices/center-for independence/handwriting-without-tears

- Denton, P. L., Cope, S. \& Moser, C. (2006). "The Effects of Sensorimotor-Based Intervention Versus Therapeutic Practice on Improving Handwriting Performance in 6- to 11- Year-Old Children". The American Journal of Occupational Therapy. 60(1): 16-27.

- Home school -curriculum.org,(2017). Handwriting Without Tears The Handwriting Curriculum, http://homeschoolcurriculum.org/handwriting-without-tears/

- Graham, S., Harris, K., Mason, L., Fink-Chorzempa, B., Moran, S., \& Saddler, B. (2008).How do primary grade teachers teach handwriting? A national survey. Reading and Writing, 21, 49-69.

- Guy, Jodie. (2003). Effect of proprioceptive input combined with Handwriting Without Tears on the handwriting of children with learning disabilities. Master's thesis. Western Michigan University, Kalamazoo, Michigan.

- Living Education Contributor,(2015). 12 Reasons Why Handwriting Is Important. https://www.thehomeschoolmom.com/12-reasons-whyhandwriting-is-important/

- Handwriting Without Tears ${ }^{\circledR}, \quad$ (2017), https://www.hwtears.com/hwt/about. 
- National Handwriting Association, (n.d) Why is Handwriting Important?. https://nha-handwriting.org.uk/handwriting/why-ishandwriting-important/

- Owens, Lisa. (2004). The effects of the Handwriting Without Tears program on the handwriting of students in inclusion classrooms. Master's thesis. Virginia Commonwealth University, Richmond, Virginia.

- Sang-Min Seo, MS, OT1. (2018). The effect of fine motor skills on handwriting legibility in preschool age children. $J$ Phys Ther Sci. $2018 \quad$ Feb; $\quad 30 \quad$ (2): 324-327. https://www.ncbi.nlm.nih.gov/pmc/articles/PMC5851374/

- Smith-Zuzovsky, Natalie and Charlotte Exner. (2004). "The effect of seated positioning quality on typical 6- and 7-year-old children's object manipulation skills." American Journal of Occupational Therapy 58 (4): 380-388.

- Ste-Marie, D.M., Clark, S. E., Findlay, L.C., \& Latimer, A. E. (2004). High levels of contextual interference enhance handwriting skill acquisition. Journal of Motor Behavior, 36, 115-27.

- Vincent Jane ,(2017). Students' use of paper and pen versus digital media in university environments for writing and reading - a crosscultural exploration. http://eprints.lse.ac.uk/69182/1/Vincent Students\%27\%20use\%20of \%20paper\%20and\%20pen_2016_published\%20LSERO.pdf

- Weintraub, N., Drory- Asayag, A., Dekel, R., Jokobovits, H., \& Parush, S. (2007). Developmental trends in handwriting performance among middle school children. OTJR: Occupation, Participation and Health, 27, 104-112. doi:10.1177/153944920702700304

- Young, S., Laxman, K. (2014). Teacher perspectives on the use of mobile devices to improve learner engagement and motivation. International Journal of Mobile Learning and Organisation. 8, 112-129.

\section{Websites: $\square$}

- https://www.lexico.com/definition/legibility

- https://www.audioenglish.org/dictionary/legibility.htm 